Calling the Police: The Use of Non-Emergency 101 in England and Wales

\title{
Introduction
}

Over the last decade there have been a number of examinations of the use of police resources, and issues of public safety, which included questions of how to provide for the same excellence in policing expected of a 21st century service, whilst managing with tighter budgets and greater limitations upon resources (Home Office, 2011). Added to this the Home Office provided for the national roll out of a non-emergency number to help support the police and public deal with many of the nuisance and non-emergency reported each year. This was nothing new. Flanagan (2008) had reported the need for additional services to deal with non-emergency calls, stating that police forces in England and Wales received as many as 67 million calls per year, many of which (he said) were inappropriate. Prior to Flanagan's findings the Home Office (2006) had stated that many of the calls received by local police forces tied up officers on calls of a non-emergency nature, which officers could do little about at that time, and thus provided little in the way of satisfaction (for the officer or the member of the public).

It is inevitable that such a magnitude of calls will affect the service that any local police authority can deliver. Thus, the development of a non-emergency provision would seem to make a great deal of sense, and evidence from local police forces would seemed to support such a need (HMIC, 2014). For example, it has been estimated that in some parts of the country (the county of Essex providing one such example), as much as 10 percent of the calls are considered inappropriate calls to an emergency number, and approximately 70 percent of this number could be considered nonemergency calls. These calls tend to fall into one of four categories: (1) inappropriate service requests - a community safety matter that is a non-emergency; (2) offensive and abusive service calls - such as calls from intoxicated members of the public; (3) irrelevant service request - such as train timetable requests; and (4) incorrect or inaccurate call - such as the failure to lock a mobile telephone keypad (Lewis, 2008). Thus, in 2010 the government set out to establish a national nonemergency number to help ease the pressures placed upon the public services (McKenna, Smith, Williams, Gardner, 2012), and to differentiate between immediate need and non-emergency.

If the call is from a member of the public who is a victim of crime, suffered threatening and/or racial intimidation, witnessed a crime, or has been injured as a result of criminal action, then these calls are more than a nuisance, and require immediate and dedicated public safety service. The police are under pressure to respond as quickly as possible, as these calls are important to the public. The police then are in an impossible position. They are expected to respond to every call, deal with and record the details of the problem - where relevant, and if possible, send an officer(s) to the location specified by the member of the public. With limited resources and spending cuts an ever present concern, a limited number of police officers cannot treat every call as an emergency. It is with this in mind that a single non-emergency number was implemented, and subsequently reviewed in this study.

\section{The Literature}

The development of a single non-emergency number, known as SNEN-101, is based on what has been referred to as the 311 'Chicago Way' (Home Office, 2004: 59). This number originally started in Baltimore, Maryland in 1996 and quickly spread to a number of other states throughout the U.S. and 
Canada. As a service, 311 was set up to provide local people with a 24/7 non-emergency number which they could call instead of dialling the 911 emergency code.

This 'idea' was also the draw for many in public safety, and the development of the single nonemergency 101 number in England and Wales. Concerned with the fear of crime and low level disorder the New Labour government published a white paper, Building Communities, Beating Crime (2004) that highlighted the impact that litter, tipping of un-wanted rubbish, graffiti and anti-social behaviour could have on the local environment and quality of life for residents and local communities. It is appropriate to note at this juncture that while the focus in this paper remains the use of a single non-emergency number, other community safety initiatives were developed at this time as well. The Police Reform Act 2002 introduced Community Support Officers (CSOs) and Local Authority Wardens (LAW), employed to patrol premises and/or the 'street' in an attempt to reduce the incident and fear of crime (Home Office 2002; Newburn, 2002). The core principles guiding the introduction of such officers was to deal with non-confrontational issues with the public, providing a uniformed visible patrol, responding to anti-social behaviour, and to deal with low level crime and quality of life issues (Home Office, 2008).

This approach has been questioned however. For example, Pamment and Ellis (2010) illustrated that young people have little to no respect for CSOs and saw them as nothing more than 'hobby bobbies' that lacked the requisite power to arrest them. This is an interesting finding similarly reflected in Mawby and Wright (2010) and Paskell (2007), and previously associated with Fielding's work, in which he noted that even within the service, community officers were often seen as 'baby kissers' (1994: 58). In contrast, others (see for example Johnson, 2005/2007; Bain, Robinson, and Conser, 2014) have stated that any 'police type' presence on the street can reduce fear of crime and anxiety of victimization, and thus increase public confidence. It was in this context that the Home Office recommended the development of a single non-emergency number (Home Office, 2004: 46-58), as low-level disorder increasingly became such a sensitive political issue (Raco, 2007; Squires, 2006).

The first stage for the development of SNEN-101 was a public consultation exercise in 2005. From this consultation, as with all public exercises, the issues were wide and varied, reflecting personal matters, condensed into eight core priorities: noisy neighbours, vandalism, littering, abandoned vehicles, intimidation and harassment, anti-social behaviour, drug-use and/or drunkenness in public places, and street lighting.

However, it is questionable whether all of these 'priorities' constitute non-emergency. For example, it would be a legitimate argument to suggest that intimidation and harassment are examples of offences which could be seen as needing an immediate response, particularly if racial or sexual in nature. Indeed, we would argue the same is true when vandalism, property damage, and/or substance misuse, present a legitimate fear, or danger to public safety.

In March 2006 the first general press statement was released which confirmed 101 as the single non-emergency number for the public to call regarding incidents of community safety. The vision, similar to Chicago, was that the police and local authorities would work side-by-side in an effort to reduce the fear of crime and improve public confidence (Home Office, 2006), and the subsequent Home Office evaluation of the pilot study found that SNEN-101 had improved public access and satisfaction. It was felt that such a service helped the police and local authorities to target their resources more effectively and efficiently and deliver services to the public. However, and perhaps somewhat surprising, the funding was withdrawn for SNEN-101 in November 2007 even though the feedback remained positive. This is even more confusing when the Home Office claimed that such an approach led to an increase in the number of calls for SNEN-101 - from 25 percent to 45 percent 
(Home Office, 2008). Additionally, as public use increased, the local police constabularies were able to gather further information, thus providing for a more accurate picture of public demand (and 'community intelligence'). Even though this was the case, the original budget of $£ 400$ million was reduced by 50 percent, perhaps a reflection of developing demands on limited resources, including the heightened awareness of terrorist attacks (in London, 2007), and the declining national and global financial stability of 2008-2011.

Sir Ronnie Flanagan (2008), then Her Majesty's Chief Inspector of Constabulary, thought the development of a single non-emergency number had been a positive move by making for a more effective partnership working, whilst also providing clear evidence of mutual benefit to the public. In part benefits can be seen in a rise in the numbers of calls, which would seem to indicate an increase in public confidence in the service - and the police more generally. It would also suggest that the implication of such a service was seen to be legitimate, if not necessary, and again shows a general sense of public consent for such programs. Regardless, a ministerial decision was taken to reduce the operational funding of SNEN-101.

In January 2008, and with little warning the Home Office decided to re-launch SNEN-101, but with the financial onus placed upon local authorities and police forces to find the necessary funding to continue the service. However, the pilot areas had employed different approaches to the service from the start, resulting in a variety of different ways in which the single non-emergency number developed. For example, in wave one (beginning in June 2006), covering 10 percent of the population of England and Wales, all counties worked to a common service blueprint. There were however local differences within these counties on the 'concept of operations.' In South Yorkshire they used existing police premises without a switchboard layer; in Hampshire they used existing police premises, but with a switchboard; South Wales built a standalone centre, and Northumbria used a network of existing police and local authority centres.

Out of these different approaches only two became well established services following the pilot; the South Wales service is now countrywide and evolved into the Welsh 'Cymru 101' service, and the Hampshire service moved to a full service for non-emergency 101 early in 2012 (BBC News, 2012), solely provided by the local police constabulary. The other services, for a variety of reasons - mostly funding issues - service provision was ended.

Mindful of the immense pressures currently being placed on all service agencies, it is perhaps timely to review the usefulness of a single non-emergency number, as there was some evidence of success. For example, Samuel (2008b) reported that approximately 750,000 calls had been received by local forces since its launch, of which 8 percent were considered issues of anti-social behaviour and community safety. This may seem a small number, but this 8 percent claimed that they would not have called any organisation for help, but the existence of 101 encouraged them to call. Indeed, data presented by McKenna, et al. (2012), suggests by the time of the national roll-out in in the summer of 2012 an estimated 2.5 million calls had been placed to SNEN-101, and in a speech to delegates at the International Crime \& Policing Conference (January 2015), the Home Secretary stated that the SNEN-101 number 'now' receives 2.5 million calls per month (May, 2015).

It is important to keep these points in mind, when reflecting upon other social/welfare services. A pilot study of ' 111 ', a non-emergency number (based on the 101 service), providing coverage

for non-emergency health care, was shown to allow the NHS to deal with serious, emergency lifethreatening cases instead of non-emergency incidents (Murphy, Alty, and Brewer, 2008).

Additionally, a similar study undertaken in Wales found positive results when pilot studies were 
assessed in both 2010 and 2012 (Griffiths, 2014). This perhaps emphasizes the validity of such an approach, with a health service similarly under pressure to reduce the burden of calls on its limited resources and to increasingly save funds while providing a universal service to the public.

The national roll out of SNEN-101 was seen as a useful way to reduce the burden on the police. Furthermore, the ease of access can produce a domino effect, where in addition to the cost saving, the delivery of services and reduced police deployments can also provide for the positive effect of supporting positive relationships between the police force and local communities. As we noted earlier, Tankebe (2013) stated that the public's perception of policing can be, and often is, effected by the perceived and actual access to information and services provided by the police. To this Bain, et al. (2014), have added that the ability of officers to do their jobs may - at least in part - be predicated upon by the important role played by the perception of fairness in policing held by local communities. Both of these views would seem to support the argument that this (non-emergency) service can increase public satisfaction by providing a 'good' 'customer' experience, which in turn increases the confidence in the police and ultimately reduces the numbers of non-emergency and inappropriate calls (Samuel, 2008b, Bain, et al., 2014). With this in mind we present the findings of our research into the usefulness of the SNEN-101 number in one region in England.

\section{Methodology}

As in the study undertaken by McKenna, et al. (2012), this research made use of a mixed methodological approach. In recent years a mixed methodology has enjoyed a rise in its use and stature within methodological discussions, and in a variety of fields of investigation, and criminal justice and public safety services should be no different. Indeed, Borkan (2004: 4) has stated that the use of a multi-methodological approach serves to '...allow the investigator to address practice and policy issues from the point of view of both numbers and narratives'. In this study we made use of semi-structured interviews and an analysis of call data provided by the local region - concentrating on volume and type of calls.

In total 50 individuals were interviewed, and included police officers (of varying rank), community safety officers, local councillors, and elected officials. Our data analysis primarily focused on the need for a $24 / 7$ service, in which the public had the opportunity to make contact with a human (person) when the need arose, and contrasts recent suggestions made by the Home

Secretary (May, 2015), that good use could be made of electronic reporting systems in order to save money and speed up the process. In conducting our research we made direct reference in our analysis to:

- the need for a single non-emergency number

- cost effectiveness

- increased information and intelligence around local issues

- partnership working

In order to consider the better capture of data, the assessment concentrated on the 'believed' increased and effective information and intelligence from having a single non-emergency number and produced a cost-benefit-saving analysis, and in order to substantiate this 'believed' effectiveness we obtained and reviewed the existing available data regarding crime, disorder and community safety in the region under review. 
Interviews consisted of a number of differing sections: (1) Business case and benefits; (2) Review of the operating phase; (3) plans for ongoing improvement and value for money; and, (4) performance and target management and evaluation. Each section consisted of a range of questions, with prepared prompts, presented as a Likert Scale. However, we also provided an additional section in which the respondent could provide a personal statement to go along with that provided on a Likert scale.

The decision was taken to examine the data from the Likert Scale using frequency and descriptive analysis only. This decision was taken as we did not want to detract from the richness of the individual statements made, and thus decided against a full statistical analysis.

\section{Findings}

In the first place individual stakeholders were invited to make a statement regarding their feelings, knowledge and understanding of the SNEN-101, as a system of operation and future direction.

Answers varied across a broad spectrum, as was to be expected as the feedback was taken from individual experience and knowledge of the service. However, negative feedback did not account for a (significantly) higher proportion than that of positive feedback. Indeed, a number of positive comments standout and support the wider findings of the research programme. For instance the comment was made that:

"We wanted to be part of it [101]... Members had 'complaints' from the public about anti-social behaviour, and believed 101 was the answer to their concerns, for example when people couldn't get an 'instant copper'." (Interview: 103).

In a similar vein, interviewee 303 stated that:

"It has gone beyond the 4-5 ASB incident types. In practice it helps [us] manage a high level of 'fear of crime' and high reporting of incidence here".

Figure 1: Is there a requirement or need to provide a 24/7 SNEN-101 service?
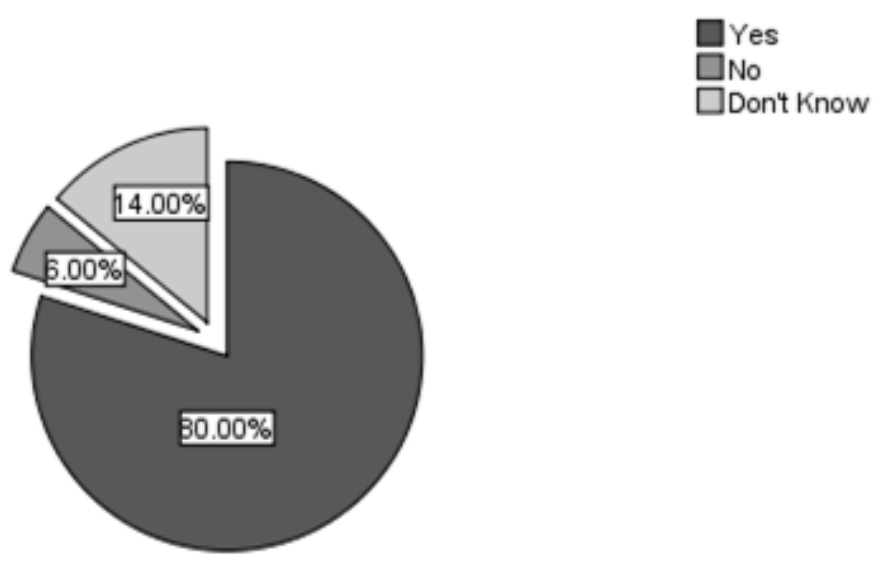

When asked if a need existed to provide SNEN-101 on a 24/7 basis, 80 percent of those interviewed (40 people) said that they felt there was a need for a 24 hour service to be provided over a 7 day week (Figure 1 above). One respondent made it clear when they stated that "Although there is 0845 for police issues, we couldn't provide 24/7 without 101".

Only 6 percent of those interviewed ( 3 people) did not think there was a requirement for a $24 / 7$ service, stating that it was either an unnecessary expense or already covered by the police, the 
remaining 14 percent of interviewees (7 people) were unsure whether such a service was needed providing comments such as:

"The service is undoubtedly helpful, but what it adds that we didn't already have... I'm not sure. There are a number of ways to deal with the issues, and perhaps it is only at night that there really is a need".

In essence this would suggest that the willingness to provide a 24/7 service was by and large, a popular view, regardless of the employment, position, or profession of the interviewees. However, when asked if they felt that SNEN-101 was a cost effective way of providing for a $24 / 7$ service, the opinion was far more mixed.

Figure 2: SNEN-101 is a cost effective way of providing a $24 / 7$ service

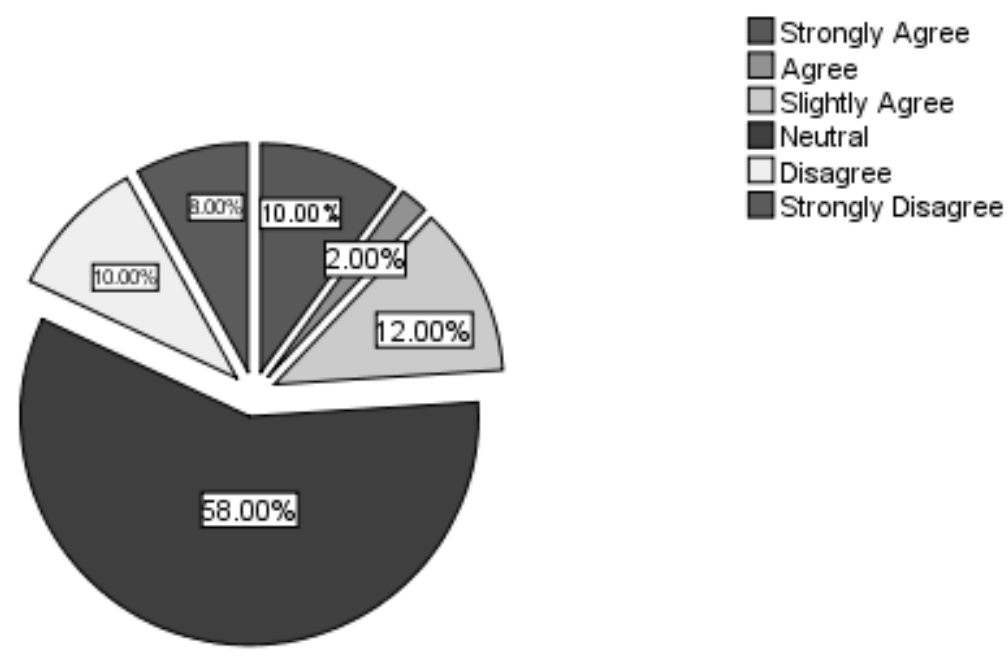

As figure 2 shows (above), a large number of people questioned were unsure of its cost effectiveness, and is perhaps reflective of the views of those who were unsure of its value as a 24 hour service. 58 percent ( 29 participants) were neutral and fell into the 'don't know' category. The 'value' of SNEN-101 becomes more questionable however, when those that saw the service as not cost effective were added. In fact, 18 percent (9 participants) believed that SNEN-101 was not cost effective (at all). This may be a reflection of peoples' concern over the cost implications to local councils, though. For example, although positive about the service as a whole, one respondent said:

"It is difficult to run because of the uncertain nature of 101 - how permanent it is... We are unsure of local position on 101. Therefore, it remains difficult to manage". Where does the money come from, and could that money be better placed?" (Interview: 207).

Finally, positive answers accounted for just 24 percent (12 people) of the total figures.

While still providing for a more positive than negative view of the service, in this question there is obvious concern regarding the large number of people who were unsure of its value. Of all issues raised the withdrawal of full funding from the Home Office, was one of the most important, and was (undoubtedly) problematic for the pilot schemes. Here, more so than anywhere else it may be important to ensure that stakeholders have all of the relevant information regarding the service provision and the outcomes from the work undertaken.

The speed of implementation also created problems in some areas in terms of planning, and securing effective, political and financial support. It is important to understand the implementation 
issues in the context of the various diverse organisations involved in the partnerships - including understanding the differences in the levels of knowledge and working practices. This is a recurring issue for community safety partnerships, and not one particular to a specific region. Indeed, Crawford (1998), Hughes and Edwards (2002), Newburn (2002), and Tilley (2005) have noted similar issues raised as a consequence of other local and governmental initiatives.

Arguably, the 'fast-time' introduction in 2006, and subsequent changes (withdrawal and re-initiation of service) is the cause of much trouble for this region. Due to such a speedy implementation local issues were perhaps not explored as well as they might otherwise have been. This was a common theme throughout the research, in which many of the respondents felt that SNEN-101 was a political innovation rather than a serious attempt to deal with community safety, and as a consequence had an ad hoc approach to its implementation.

A number of questions were designed to understand how 'data' captured was used in dealing with issues of community safety. For example, respondents were asked if they felt that SNEN- 101 had increased information and intelligence around local issues.

Figure 3: Has SNEN-101 contributed to increased information and intelligence around local issues?

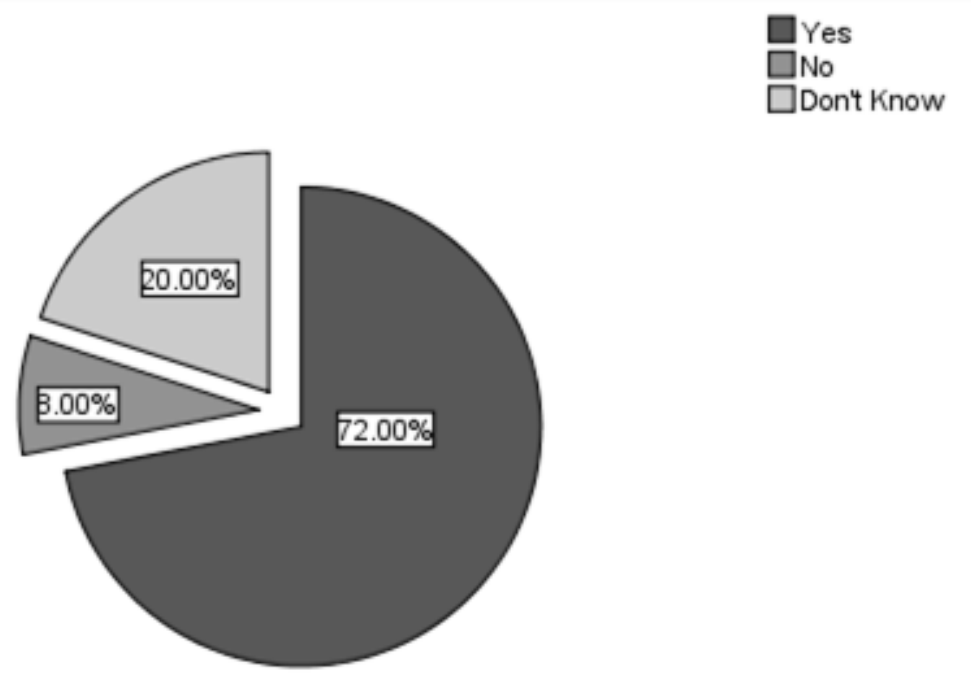

The feedback provided by participants suggests an extremely positive view with regards to the contribution made by SNEN-101 to support an increase in information and intelligence gathering (see figure 3 -above), and the following statements were broadly typical of feedback received from practitioners:

"Practitioners are very supportive as 101 has given an extra amount of local information and enhances services" (Interview: 506).

and

"101 is about being out there. 101 gives us lots of information and lots of local intelligence we didn't have. This is what we have been waiting for" (Interview: 201).

In all, 72 percent (36 people) said that they felt SNEN-101 had provided for better information and intelligence concerning local issues and events, with only 28 percent saying that there were unsure (14 respondents), and 8 percent clearly saying it provided no 'new' intelligence at all (4 people). 
The data generated by the local Police Authority suggested that there was a continued growth of information and intelligence around specific activities, which could then be used to further improve the effective deployment of resources, and adding value in terms of the time and resource savings. For example, during the 18 month period of research, SNEN-101 was frequently used to report incidences of rowdyism (28\%); harassment (20\%); noise (19\%); abandoned vehicles (9\%); vandalism (6\%); and drunken behaviour (5\%). Drugs, graffiti, fly-tipping, etc. were all at or below $2 \%$, which show a mixed need for both community safety and environmental health action.

Such 'information' was welcomed by all parties, particularly by the police, reiterating the position that the data helped with deployment of limited resources, increasingly important with pending cuts to provision of public service (Travis, 2015). Indeed, it seems that in recent years there has been a cut to public spending in policing and associated services with each budget, and - as part of a costcutting exercise - has most recently seen the Home Secretary announce that local police chiefs should have a greater ability to redistribute funds as appropriate (Travis, 2015).

There was however, a worryingly negative view of the ability of SNEN-101 to provide for improved partnership working. The response is one that is familiar to research on partnership working (Crawford, 1998; Gilling and Barton, 1997; Gilling, 1997; Hughes and Edwards, 2002; Hughes, McLaughlin, and Muncie, 2002; and Tilley, 2005), and further outlined in Graph 1 - below.

Graph 1: Has 101 Improved Partnership Working?

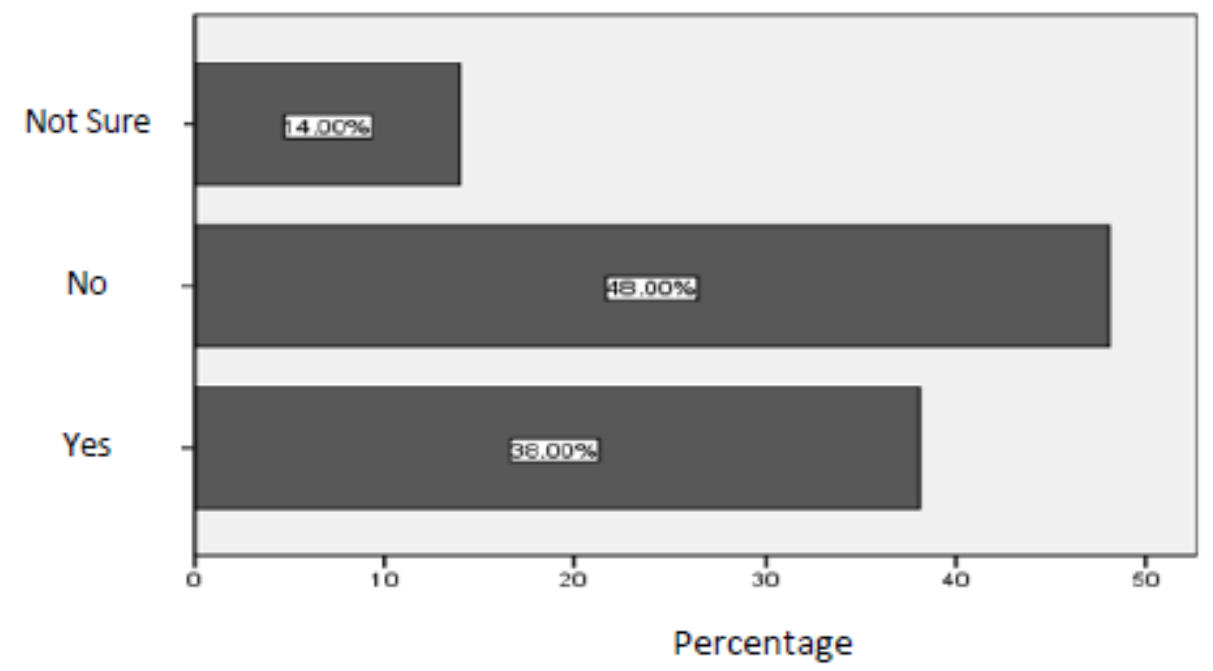

The evidence provided in Graph 1 shows that in the largest group (the majority if you will), 48 percent ( 24 people), felt that there were no improvements in the ways in which partnerships were working. 38 percent (19 interviewees) were more positive about the ways in which partnerships were working, but this may have been individuals that previously felt they had little input to the partnership or lacked information exchange in the past. Most of the people interviewed answered this question from the point of view of the 'agency' they were employed by. This is understandable, but there was little reflection on how the problem(s) of working with another 'agency' affected the partnership more generally. This was a clear indication of how people measured success and what each factor meant and the terms of the outcome.

For example, while 48 percent said that they did not feel that SNEN-101 had provided for a better working relationship, the consensus from our interviews was that 'good' working relationship's 
already existed prior to SNEN-101 and so had little impact on working relationships. Indeed, one respondent stated that:

"101 has made no contribution to partnership working here. All agencies meet every 2 weeks any way to discuss a range of problems - community safety is always one of them". (Interview: 204)

However, the provision of improving partnership working is a key factor in the success of SNEN-101 (and any community safety initiative) and its ability to achieve cost savings, increase access and delivery of local services, with a reduction in non-emergency calls to the police. Dealing effectively with the expectation and satisfaction of the general public are further important areas in discussions of success, and vital - if there is a consideration to maintain any community safety service.

As a final check, stakeholders were asked if they felt that partnership working had improved through the introduction of a single non-emergency number, and answers were proportionately balanced. Although the tendency leaned toward the positive, only 2 percent ( 1 interviewee) strongly agreed with the statement, 34 percent (17 interviewees) overall felt that partnership working had improved in some way. Where 32 percent (16 interviewees) disagreed - to some extent. This is further highlighted below in figure 4: partnership working has improved through a SNEN-101.

Figure 4: Partnership working has improved through a SNEN-101

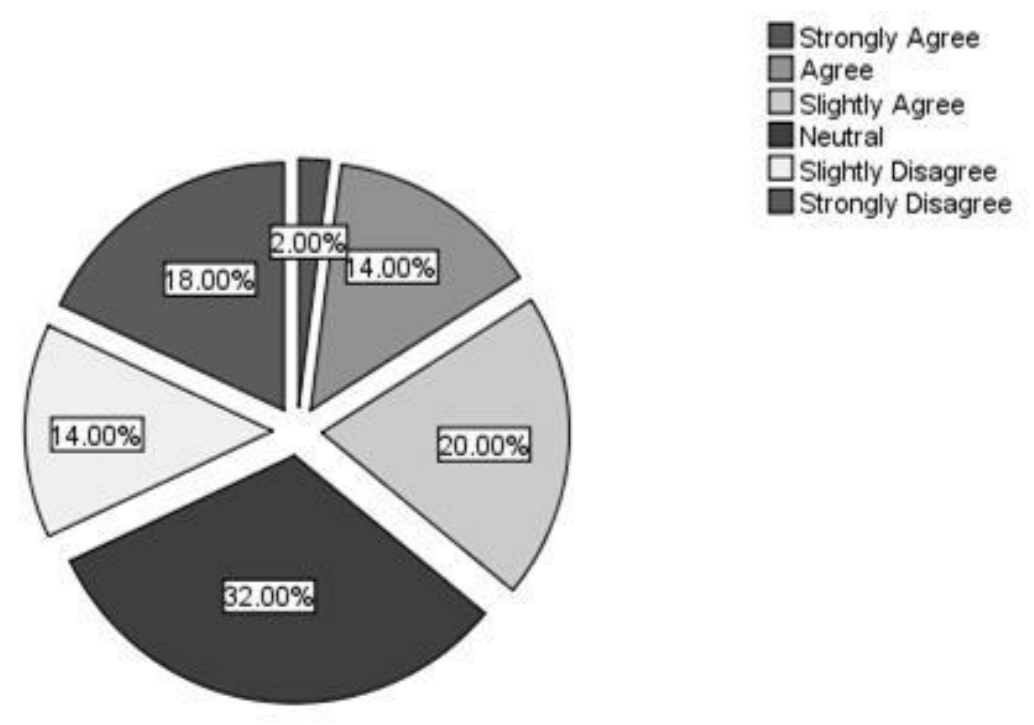

This is a worrying trend, because if the stakeholders have little belief in the service it would seem to be even harder to sell it to the public as a strong alternative to them using the emergency-999 number. A position made more concerning with the statement by the Home Secretary that could see community officers and volunteers given greater powers in an effort to reduce policing budgets still further (Dodd, 2015).

Significantly, when asked to comment upon the transformational cost savings stakeholders were again split in their findings and understanding, and thus lacked any positive support. 
Graph 2: Has SNEN-101 provided for transformational cost savings and efficiencies?

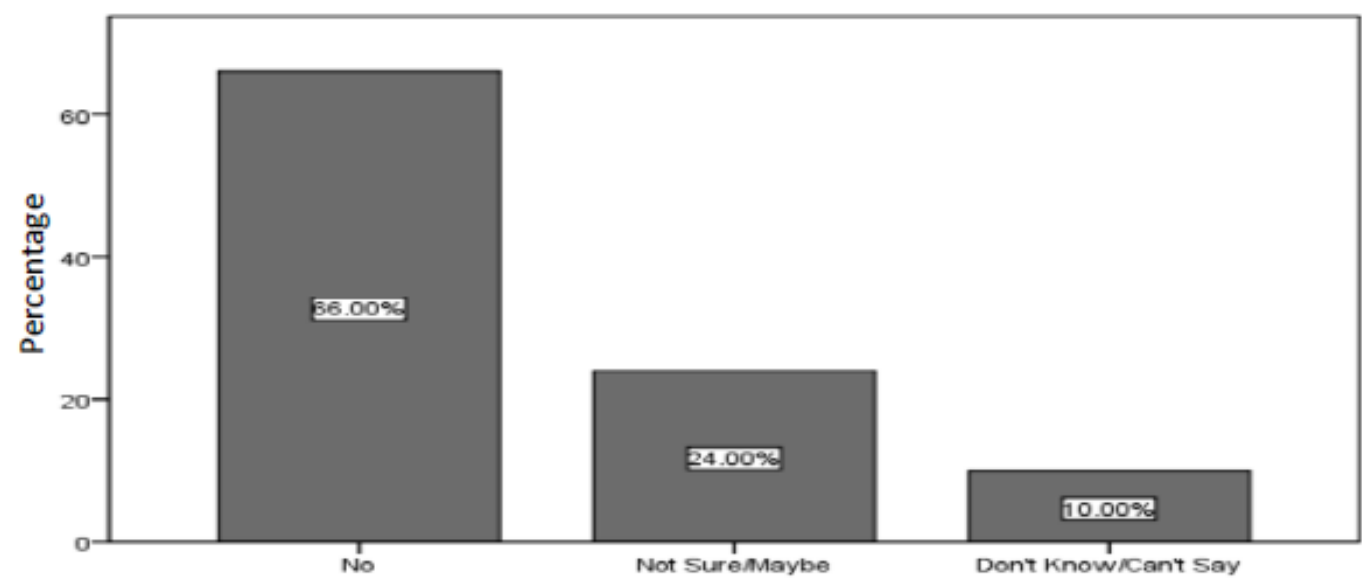

10 percent of participants ( 5 people) stated that they did not know of transformational cost savings, and a further 24 percent (12 participants) were not sure. The final, and by far the largest group, 66 percent (33 individuals) said that they believed that SNEN-101 had not provided for any transformational cost savings. Although a little concerning, it is not surprising. For instance, many stakeholders felt that there was a great deal of duplication from individual service providers in regards to SNEN-101, and that in order to reduce/transform cost, the use of SNEN-101, needed full support from the Home Office, which - amid all the cost savings and budget reductions was never really certain, or guaranteed. However, senior officers seemed more positive of the service. For example, one senior police officer commented that:

"As an additional policing service it helps - a lot. It frees us up to deal with things of a lifethreatening nature... We are able to respond as it [crime] happens - it is proactive rather than reactive (Interview: 201). Another added that:

"We learn about more problems and we are able to intervene more often" (Interview: 507).

\section{Discussion}

It appears that a single non-emergency number is a worthwhile scheme, popular with both the public (Home Office, 2006) and senior politicians. However, if a single non-emergency number is to be successful, questions of its cost effectiveness need to be resolved. The issue of

cost-effectiveness is - inevitably - open to some interpretation. Most of those interviewed saw cost as a single issue relevant to them if they were expected to contribute greater funding to the running of the service as policing budgets were reduced, or budgets redirected. The majority of those interviewed thought it a worthwhile service (80\%) but continued to question its worth once the issue of funding the service arose. Indeed, we have some sympathy for this expression, since from the start the funding for SNEN-101 has been inconsistent, making it difficult for 'regions' to plan ahead and make a sound proposal. If the intention is to provide a single non-emergency number into the future, the funding streams available to local areas must be made clear.

Furthermore, SNEN-101 brought knowledge and intelligence of the local community to the attention of the police. Such knowledge of a local community, its social problems, its demographics, etc. are invaluable when providing such service(s), particularly in reference to such emotive issues as crime and community safety. The single non-emergency number is thus of great use - if not importance. Perhaps one of the greatest divisions between authorities and the local community, is the lack of 
communication, or negative interactions (Bain, et al., 2014), and SNEN-101 is capable of satisfying this and many other aims. A single non-emergency number will, for example, reduce calls to emergency only numbers like '999'; provide public reassurance that something is being done to tackle crime/anti-social behaviour; and increase access to services.

However, there are the problems that arise as a direct result of the evidence presented here. In the first place, positive affirmation only follows positive action, and part of that is communication. We raise this here, because of recent suggests made that 'cost savings' could be made through the use of automated and/or electronic reporting services, where victims would be asked to report crime via the internet (May, 2015). Evidence from innumerable studies would seem to suggest that the comfort provided by human contact can help to repair the damage caused through experiencing crime as a victim - no matter the crime. Indeed, the International Association of Chiefs of Police (IACP, 2010: 3) has stated that:

Law enforcement personnel have vital roles to play in responding to and supporting victims of crime. Crime victims are key stakeholders... [who] hold unique perspectives, valuable insights, active interest in the problem, and strong feelings about criminal behavior. Responding effectively and appropriately to all victims is not only the right thing to do... but it is also in law enforcement's best interest.

The question then is just how much will be saved, if the net result is a requirement to redeploy services in other areas where evidence, intelligence or community support is lost.

A single non-emergency number will only help those 'responsible' members of the public who call regarding matters of community safety and anti-social behaviour rather than for some irrelevant and/or insignificant personal reason. The non-emergency number can be advertised, and the public can be educated to use it, but only if they are willing to listen. In England, at least, there is perhaps a section of the public that will still call the emergency services for the most trivial matters. These calls will on the basis of past experience still happen, even following development of a (national) single non-emergency number, and a high profile campaign, and there are a number of reasons for this. In the first place, what one believes is trivial is all consuming to another. For example, what begins as a single event of a trivial nature, can quickly deteriorate into a perceived threat to personal space if the behaviour continues - noisy neighbours, groups of youth hanging around in parks and community spaces, are just some examples. Similarly, it must be remembered that after more than 70 years of using the emergency 999 number, the U.K. might find that it will take some time before the public calls the relevant and appropriate number for entirely the right reason.

In support of the findings of Bain, et al. (2014), McKenna, et al. (2012), and Samuel (2008b) discussed previously, we were able to confirm that a police presence on the streets (of any type) helped reduce the fear of crime to some extent, which in turn only further supported the evidence for SNEN-101 acting to provide invaluable information to the police on what was 'happening' on the housing estates and local streets. In this example it seems that SNEN-101 is a valuable/valued service, which needs careful support and evaluation over time in order to improve the service and provide the general public with the level of support they demand. We believe that much more time and effort should be put into the investigation of this and other similar services, in order to continue to improve the already increasingly positive relationship between local communities, policing agencies and local authorities. 


\section{References}

Bain, A., Robinson, B. K., and Conser, J. (2014). Perceptions of Policing: Improving Communication in Local Communities, International Journal of Police, Science \& Management, Vol. 16 (4): 267-76

BBC News (2012, January, 11th). Hampshire Police moves to 101 non-emergency number,

BBC NEWS - Hampshire \& Isle of Wight, available at: http://www.bbc.com/news/uk-englandhampshire-16515698

Borkan, J. (2004). Mixed methods studies: A foundation for primary care research, Annals of Family Medicine, Vol. 2 (1): 4-6

Crawford, A. (1998). Crime Prevention and Community Safety: Politics, Policies and Practices, Addison Wesley Longman: Essex

Dodd, V. (2015, May 17th). Police warn budget cuts will lead to 'paramilitary' force, The Guardian, available at: http://www.theguardian.com/uk-news/2015/may/17/police-warn-big-budget-cuts-willlead-to-paramilitary-force

Fielding, N. (1994). Cop Canteen Culture, in T. Newburn, and E.A. Stanko (eds.) Just Boys Doing Business: Men, Masculinities and Crime, London: Routledge

Flanagan, R. (2008). First Contact: A Thematic Inspection of Police Management: Summary. London: HMIC

Gilling, D. (1997). Crime Prevention: Theory, Policy and Politics, University of College London Press, London

Gilling, D. and Barton, A. (1997). Crime prevention and community safety: A new home for social policy, Critical Social Policy, Vol. 17 (52) 63-83

Griffiths, W. (2014). The Griffiths' Review: Non-emergency Patient Transport. Final Report, Health and Social Services Directorate, Welsh Assembly Government: Cardiff, Wales

Hamai, K., and Ellis, T. (2006). Crime and criminal justice in modern Japan: From re-integrative shaming to popular punitivism, International Journal of the Sociology of Law, Vol. 34 (3): 157-78

Hamai, K., and Ellis, T. (2008). Japanese criminal justice: Was re-integrative shaming a chimera? Punishment and Society, Vol. 10 (1): 25-46

Home Office (2011). A New Approach to Fighting Crime, London: Home Office Home Office (2008). From Neighbourhood to the National: Policing our Communities Together, London: Home Office

Home Office (2006). 101 new single non-emergency number, London: Home Office

Home Office (2004). Building Communities, Beating Crime, London: Home Office

Home Office (2002). Police Reform Act 2002, London: Home Office

Home Office (1998). Crime and Disorder Act 1998, London: Home Office

HMIC (2014). Policing in Austerity: Rising to the challenge. Compendium - Practical examples from the 2013 valuing the police inspections, London: Home Office 
HMIC (2004). Thematic Report: Modernising the Police Service, London: Home Office

HMIC (2001). Open All Hours Her Majesty's Inspectorate of Constabulary's Thematic Inspection of Public Reassurance. London: HMIC

Hughes, G., and Edwards, A. (2002). Crime Control and Community: The new politics of public safety, Willan Publishing: Devon

Hughes, G., McLaughlin, E. and Muncie, J. (2002). Crime Prevention and Community Safety: New Directions, Open University Press: London

IACP (2010). Enhancing Law Enforcement Response to Victims: Training Supplement, Washington (D.C.): U.S. Department of Justice

Johnson, L. (2007). 'Keeping the Family Together'. Police Community Support Officers and the 'Police Extended Family' in London, Policing and Society, Vol. 17 (2): 119-140

Johnson, L. (2005). From 'community' to 'neighbourhood' policing: police community support officers and the 'police extended family' in London, Journal of Community and Applied Social Psychology, Vol. 15 (3): 241-254

Lewis, L. (2008). Help! Police! Quick! I can't stop my ice cream melting, The Times: August 9, 2008, p. 43.

Loveday, B. (2008). Workforce Modernisation in the Police Service, International Journal of Police Science and Management, Vol. 10 (2): 136-144

May, T. (2015, January 28th). Theresa May announces new f10million Police Knowledge Fund, Speeches: Home Secretary at the International Crime \& Policing Conference, The King's Fund, London, available at: https://www.gov.uk/government/speeches/home-secretary-at-theinternational-crime-policing-conference

Mawby, R.C., and Wright, A. (2010). The police organisation, in T. Newburn, (ed.) The Handbook of Policing, London: Sage Publications

McKenna, K., Smith, N., Williams, J., and Gardner, R. (2012). Rolling out the police single nonemergency number (101): research into the public's and practitioner's views. Research Report 66, London: Home Office

Murphy, O. Alty, J and Brewer, A. (2008). The Three Digit Number For Urgent Care Concept Research, Department of Health; London

Newburn, T. (2002). Community safety and policing: some implications of the crime and disorder act 1998. In: G. Hughes, E. McLaughlin, and J. Muncie, (eds.) Crime prevention and community safety: new directions. Open University and Sage Publications, London, pp. 102- 122

Pamment, N., and Ellis, T. (2010). A retrograde Step: The Potential Impact of High Visibility Uniforms within Youth Justice Reparation, The Howard Journal, Vol. 49 (1) 18- 30

Paskell, C. (2007). 'Plastic police' or 'community support'? The role of police community support officers within low-income neighbourhoods, European Urban and Regional Studies, Vol. 14 (4): 349361

Raco, M. (2007). Securing Sustainable Communities Citizenship, Safety and sustainability in the New Urban Planning, European Urban and Regional Studies, Vol. 14 (4), 305-320 
Samuel, T. (2008a). Crime Reduction - Helping to Reduce Crime in Your Area: 101: The single nonemergency number London: Home Office

Samuel, T. (2008b). The Single non-emergency number: An Introduction to 101. London: Home Office.

Sturcke, J (2010). Police under investigation over Fiona Pilkington case, The Guardian, available at: http://www.guardian.co.uk/uk/2010/mar/16/police-under-investiation-fiona-pilkington

Squires, P. (2006). New Labour and the politics of antisocial behaviour, Critical Social Policy, Vol. 26 (1): $144-168$

Tankebe, J. (2013). Viewing things differently: The dimensions of public perceptions of police legitimacy, Criminology, Vol. 51 (1): 103-136

Tilley, N. (2005). Handbook of Crime Prevention and Community Safety, Willan Publishing, Devon Travis, A. (2015, September 9th). Home Secretary warns over reduced police budgets, The Guardian, available at: http://www.theguardian.com/uk-news/2015/sep/09/home-secretary-police-budgetstheresa-may

Travis, A. (2010, March 1st). Brown revives 101 Scheme for reporting antisocial behaviour, The Guardian, available at: http://www.theguardian.com/uk/2010/mar/01/antisocial-behaviour-101number 